\title{
Promising Effect of Processing Parameters on Yarn Properties in Rotor Spinning
}

\author{
Rajib Al Mamun", Md. Reazuddin Repon ${ }^{1, *}$, M. Tauhidul Islam ${ }^{2}$, K.Z.M. Abdul Motaleb ${ }^{1}$ \\ ${ }^{1}$ Department of Textile Engineering, Khwaja Yunus Ali University, Bangladesh \\ ${ }^{2}$ Institute of Radiation and Polymer Technology, Bangladesh Atomic Energy Commission, Bangladesh
}

Copyright $\bigcirc 2017$ by authors, all rights reserved. Authors agree that this article remains permanently open access under the terms of the Creative Commons Attribution License 4.0 International License

\begin{abstract}
Fabric characteristics significantly depend on the physical properties of yarn and the qualities of rotor yarn greatly governed by processing parameters. The aim of this study is to observe the effect of processing parameters such as rotor diameter and speed on the physical properties of yarn in rotor spinning process. Mixing of spinning waste with the virgin cotton is a common phenomenon in rotor spinning. 0.11 sliver hank of $100 \%$ cotton fibre with $65 \%$ virgin cotton and $35 \%$ wastage was used to produce $12 \mathrm{Ne}$ yarn. The favorable impact of processing parameters on the yarn characteristics were accessed by co-efficient of variation $(\mathrm{CVm} \%)$, imperfection index (IPI), hairiness, tenacity, count strength product (CSP) and force at break. The yarn qualities were improved with increasing of rotor speed and rotor diameter.
\end{abstract}

Keywords Rotor Spinning, Rotor Diameter, Rotor Speed, Hairiness, Imperfection, Yarn Strength

\section{Introduction}

The process of converting fibers into yarn is complex which requires many investigations and new technical \& technological solutions [1]. There are many spinning systems are available such as ring spinning, air vortex spinning, friction spinning, disc spinning, solo spun spinning, Siro spinning, air jet spinning, wrap spinning and rotor spinning [2]. The best process of producing better quality yarn from very poor grade of cotton and even from wastage is rotor spinning. Rotor spinning system is rising due to the considerable reduction in space and personnel [24]. The volume of production on rotor spinning has also increased in recent years which are quite understandable considering the present trend in the production and consumption of textile products [5]. Rotor spinning gives a new era to produce more uniform, fuller, aerated and regular in strength cotton yarn [6]. Rotor spinning is a recognized spinning system mainly for medium and course counts. The yarn characteristics of rotor spun yarn are affected by many factors mainly related to raw material, machine and processing parameters.

Many researchers have already studied the effect of rotor and carding parameters on yarn quality from different outlooks [7-10]. The results of several investigations have revealed that machine parameters significantly affect the physical and mechanical properties of yarn [11-13]. Rotor yarns are less irregular compared to the ring spun yarn because of multiple doubling or back doubling of fibres in the rotor groove. In addition, rotor spun yarns are not as affected by roller drafting wave as ring yarns [4].

No work has so far been observed on the yarn properties produced from $65 \%$ virgin cotton and $35 \%$ wastage of 12 Ne yarn.

Widely used natural fibre in the world around $35 \%$ of total world fibres is cotton which provides the natural comfort, soft hand, durability, visual appeal, good absorbency and reasonable strength $[14,15]$ and these are the main reasons for selecting cotton fabrics in this study.

The objective of this experiment was to disclose the effect of rotor speed from 35,000 to 45, $000 \mathrm{rpm}$ and rotor diameter from 43 to $66 \mathrm{~mm}$ on yarn characteristics and produce the quality cotton yarn by using rotor spinning system that can be used for weaving and knitting fabrics. Yarn quality basis on CVm\%, IPI, Hairiness, Tenacity, CSP and force at break properties were investigated systematically.

\section{Materials and Methods}

\subsection{Materials}

The slivers of 0.11 hank with $65 \%$ virgin cotton and $35 \%$ wastage (10\% droppings $1,10 \%$ droppings $2,10 \%$ noil and $5 \%$ pneumafil) were collected from Akij Spinning Mills Limited, manikganj, Bangladesh. Table 1 indicates the cotton fibre properties used in this experiment those were assessed by Uster- HVI instrument according to the 
standard testing condition [16].

Table 1. Properties of cotton fibre

\begin{tabular}{|c|c|}
\hline Quality parameters & Value \\
\hline Spinning Consistency Index & 138 \\
\hline Micronaire ( $\mu \mathrm{g} /$ inch) & 3.00 \\
\hline Maturity Index & 0.87 \\
\hline Length(mm) & 28.00 \\
\hline Uniformity Index (\%) & 80.0 \\
\hline Short fibre index (\%) & 8.2 \\
\hline Strength (g/tex) & 30.4 \\
\hline Elongation (\%) & 6.0 \\
\hline Moisture (\%) & 7.1 \\
\hline Reflectance (\%) & 75.6 \\
\hline Yellowness (degree) & 9.3 \\
\hline
\end{tabular}

\subsection{Methods}

\subsubsection{Sampling}

Different samples are identified as mentioned table 2.

Table 2. Sample Identification

\begin{tabular}{|c|c|}
\hline Sample types & Identification \\
\hline $\begin{array}{c}\text { Yarn from } 43 \mathrm{~mm} \text { rotor diameter and rotor speed } \\
35,000 \mathrm{rpm}\end{array}$ & $\mathrm{A}$ \\
\hline $\begin{array}{c}\text { Yarn from } 43 \mathrm{~mm} \text { rotor diameter and rotor speed } \\
40,000 \mathrm{rpm}\end{array}$ & $\mathrm{B}$ \\
\hline $\begin{array}{c}\text { Yarn from } 43 \mathrm{~mm} \text { rotor diameter and rotor speed } \\
45,000 \mathrm{rpm}\end{array}$ & $\mathrm{C}$ \\
\hline $\begin{array}{c}\text { Yarn from } 54 \mathrm{~mm} \text { rotor diameter and rotor speed } \\
35,000 \mathrm{rpm}\end{array}$ & $\mathrm{D}$ \\
\hline $\begin{array}{c}\text { Yarn from } 66 \mathrm{~mm} \text { rotor diameter and rotor speed } \\
35,000 \mathrm{rpm}\end{array}$ & $\mathrm{E}$ \\
\hline
\end{tabular}

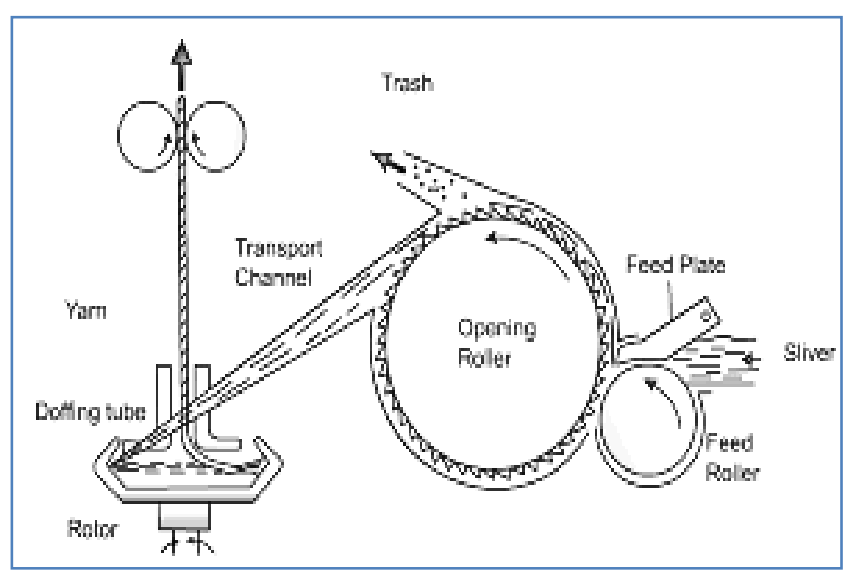

Figure 1. Basic principle of rotor spinning process

\subsubsection{Spinning Process}

Rotor spinning machine (BD 200RN, Elitex, Czech Republic) was used. Firstly, drawn slivers were feed through a sliver guide via a feed roller and feed plate to rapidly rotating opening roller. The rotating teeth of the opening roller comb out the separate fibers from the sliver clamped between feed plate and feed roller. Then the fibers were feed to inside wall of the rotor after completing action in transport channel. The fibres moved forward to the rotor groove from the conical rotor wall by centrifugal forces in the rapidly rotating rotor. Finally, the yarn formed in the rotor is continuously taken off by the delivery shaft and the pressure roller through the nozzle and the draw off tube and wound onto a cross wound package.

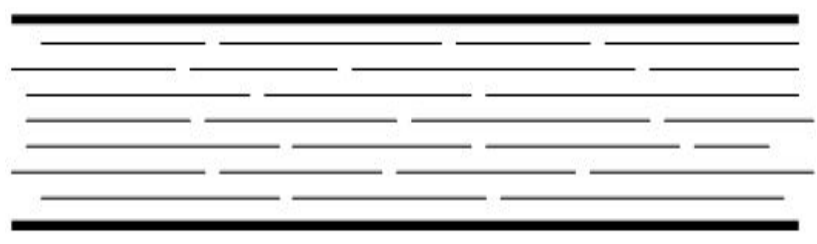

Figure 2. Ideal fibre assemblies with perfect evenness

\subsubsection{Testing of samples}

Uster Tester-5 was used to determine the unevenness and imperfection (IPI) of the yarn at a speed of $450 \mathrm{~m} / \mathrm{min}$. The observed parameters were $\mathrm{Um} \%, \mathrm{CVm} \%$, thin places ($50 \%)$, thick places $(+50 \%)$, neps $(+280 \%)$ and hairiness. The imperfection (IPI) is the sum of no. of mass increase (thick places), mass reductions (thin places), and short mass increases (neps).Tensile properties viz., yarn tenacity and force to break were measured at Uster Tensojet-4 at a speed of $200 \mathrm{~m} / \mathrm{min}$. Average of ten tests was taken for final result at each trial. All experiments were performed at temperature $20 \pm 2{ }^{\circ} \mathrm{C}$ and relative humidity $65 \pm 2 \%$.

Yarn count was determined through the digital auto sorter-5 linked with compute system, which gives direct reading. Lea strength tester was used to find the lea strength in pounds according to the ASTM (1997) method. Count strength product (CSP) was calculated by multiplying the yarn count with Lea strength according to the British Standard (1985) [56]. Equation 1 was used to measure CSP.

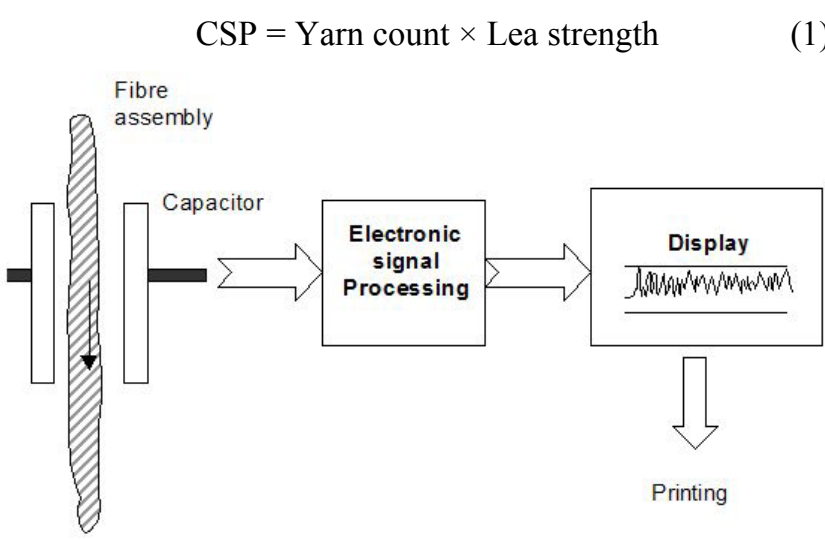

Figure 3: Principle of Uster evenness tester

\section{Results and Discussion}

\subsection{Yarn Unevenness}

\subsubsection{Irregularity $\mathrm{CVm} \%$}


The figure 4 is representing the positive impact of rotor speed and rotor diameter on $\mathrm{CVm} \%$ of the yarn. $\mathrm{CVm} \%$ were decreased with the increment of rotor speed and rotor diameter. Concerning $\mathrm{CVm} \%$, the order of samples were found as $\mathrm{A}>\mathrm{B}>\mathrm{C}$ for rotor speed and $\mathrm{A}>\mathrm{D}>\mathrm{E}$ for rotor diameter. For rotor diameter $43 \mathrm{~mm}$, the $\mathrm{CVm} \%$ were decreased $8.14 \%$ and $16.21 \%$ respectively for the samples $\mathrm{B}$ and $\mathrm{C}$ as compared to $\mathrm{A}$. It has been also found that at $35,000 \mathrm{rpm}$ rotor speed, the $\mathrm{CVm} \%$ were decreased $0.84 \%$ and $6.61 \%$ respectively for the samples D and E compared to the sample A.

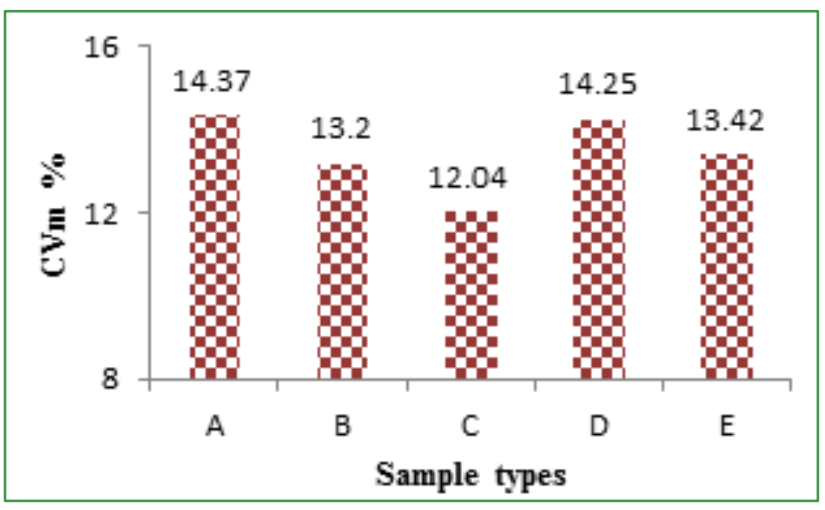

Figure 4. Effect of rotor speed and diameter on yarn $\mathrm{CVm} \%$

\subsubsection{Imperfection}

Figure 5 shows the effect of rotor speed and diameter on yarn imperfections properties. The yarn imperfection values were decreased with the increment of rotor speed. No chronological impacts were noticed due to increase of rotor diameter. At higher rotor speed, the velocity of fibers inside the transport channel increases and fibers may be transported to the rotor groove in a substantially more uniform way of smaller size tufts. The vice-versa relations of imperfection and rotor speed are due to better affidavit of individualized fibers at higher suction of air pressure [17]. Regarding imperfections, the order of samples were found as $\mathrm{A}>\mathrm{B}>\mathrm{C}$ for rotor speed variation and $\mathrm{D}>\mathrm{A}>\mathrm{E}$ for rotor diameter variation respectively. The imperfections were decreased $45.51 \%, 51.40 \%$ and $46.26 \%$ for the samples B, $\mathrm{C}$ and $\mathrm{E}$ respectively as compared to A. Oppositely, the values was increased $79.91 \%$ for $\mathrm{D}$.

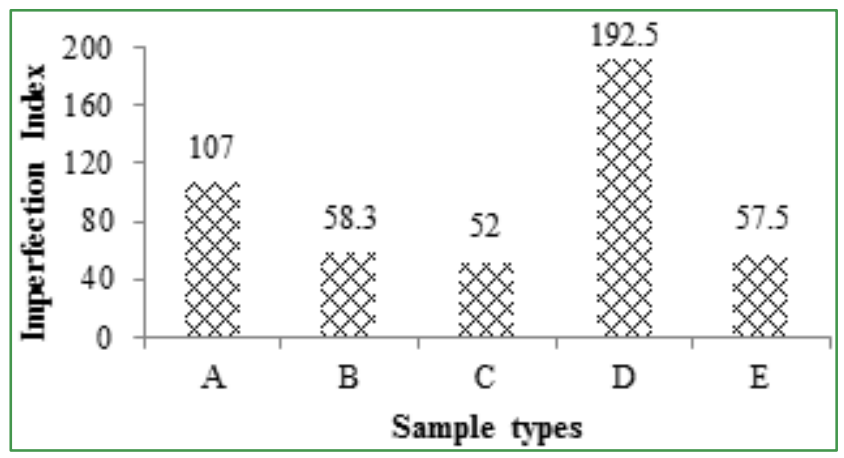

Figure 5. Effect of rotor speed and diameter on yarn imperfection

\subsubsection{Hairiness}

Figure 6 illustrates the effect of rotor speed and rotor diameter on yarn hairiness. Yarn hairiness is a complex concept, which generally occurs because some fibre ends protrude from the yarn body, some looped fibres arch out from the yarn core and some wild fibres in the yarn. The yarn hairiness $\mathrm{H}$, is one of the most important parameters influences the performance of subsequent processes like weaving, knitting or dyeing as well as the appearance and end use of the final fabric or garment. Rotor speed and rotor diameter has positive and negative impact on yarn hairiness. Regarding hairiness, the order of samples were found $\mathrm{C}>\mathrm{A}>\mathrm{B}$ for variation of rotor speed and $\mathrm{E}>\mathrm{A}>\mathrm{D}$ for variation of rotor diameter. The hairiness was decreased $7.80 \%$ for the sample B and $1.69 \%$ increased for the sample $\mathrm{C}$ at constant rotor diameter of $43 \mathrm{~mm}$. It was also found that the hairiness was $11.18 \%$ decreased for the sample D and $2.34 \%$ increased for the sample $\mathrm{E}$ at constant rotor speed $35,000 \mathrm{rpm}$.

The higher values of rotor speed and diameter are liable for adverse impact on hairiness. The hairiness is greatly relies on the fiber transports to rotor and fiber collection in the rotor groove. Centrifugal forces and a vacuum in the rotor housing causes the fibers to disengage at a certain point from the opening roller and to move via the fiber channel to the inside wall of the rotor. Therefore, increased rotor diameter boost the disengagement which result in adverse yarn hairiness properties. Oppositely, the centrifugal forces in the rapidly rotating rotor cause the fibers to move from the conical rotor wall toward the rotor groove and be collected there to form a fiber ring. So, extremely higher rotation of rotor also enhances the disentanglements of fibers which lead hairiness properties as well [18].

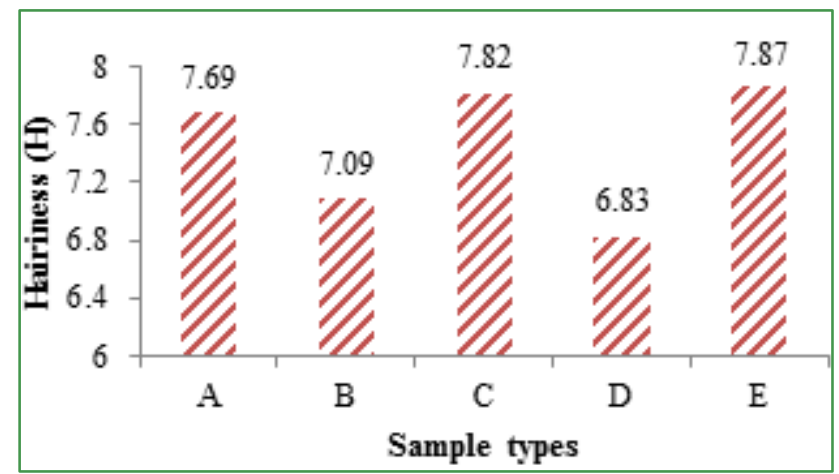

Figure 6. Effect of rotor speed and diameter on yarn hairiness

\subsection{Yarn Strength}

\subsubsection{Tenacity}

Yarn tenacity, is one of the most important parameter influencing the yarn's use in terms of quality. The most important forces acting on the yarn inside the rotor is the centrifugal force [19]. However, higher centrifugal force will be resulted at higher rotor speed that performs better 
consolidation of fibers which in turn will lead to higher yarn strength. The higher rotor speed improves the yarn strength by ensuring better binding of fibers. From figure- 7 , it is clearly seen that yarn tenacity has been increased with the increase of rotor speed and rotor diameter. The order of samples were found as $\mathrm{A}<\mathrm{B}<\mathrm{C}$ in terms of tenacity due to rotor speed variation and $\mathrm{A}<\mathrm{D}<\mathrm{E}$ was found for rotor diameter variation. The tenacity of $\mathrm{B}$ and $\mathrm{C}$ were increased by $32.53 \%$ and $54.62 \%$ respectively with respect to A. Equally, the tenacity $18.61 \%$ increased for D and $31.21 \%$ increased $\mathrm{E}$ compared to the sample $\mathrm{A}$ at constant rotor speed.

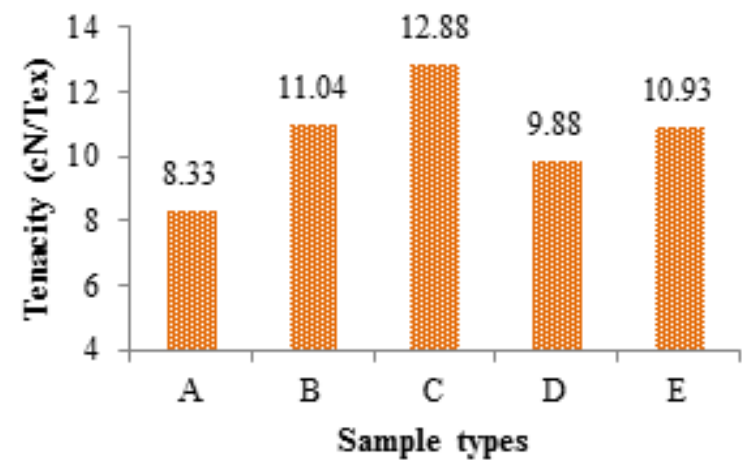

Figure 7. Effect of rotor speed and diameter on yarn tenacity

\subsubsection{Count Strength Product}

Rotor speed and rotor diameter have significant effect on the yarn count strength product (CSP). From figure 8 , it is clearly evident that, the CSP increase with the increment of rotor speed and rotor diameter. The order of samples were found as $\mathrm{A}<\mathrm{B}<\mathrm{C}$ in terms of CSP due to rotor speed variation $\mathrm{A}<\mathrm{D}<\mathrm{E}$ was found for rotor diameter variation.. The CSP values of $B$ and $C$ were increased by $17.57 \%$ and $27.41 \%$ respectively with respect to A. Conversely, the CSP value $18.69 \%$ increased for $54 \mathrm{~mm}$ diameter and $28.88 \%$ increased for $66 \mathrm{~mm}$ diameter compared to the sample produced from $43 \mathrm{~mm}$ diameter at constant rotor speed of $35,000 \mathrm{rpm}$.

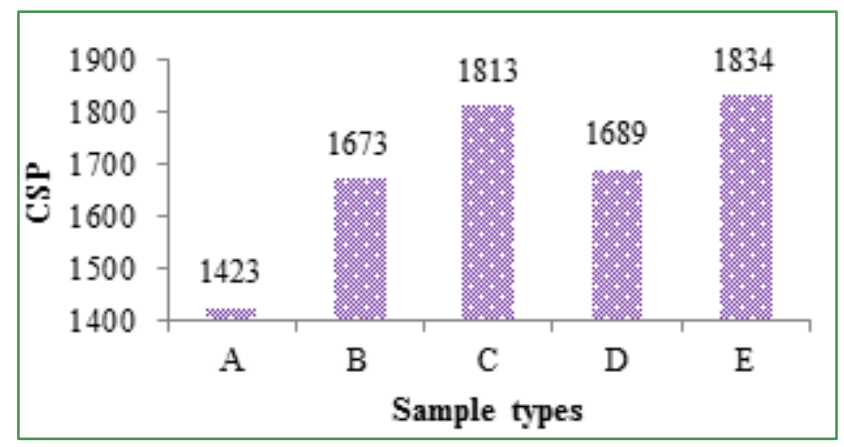

Figure 8. Effect of rotor speed and diameter on yarn CSP

\subsubsection{Force to Break}

Figure 9 demonstrates the effect of rotor speed and rotor diameter on yarn force to break. The value of force to break was increased with the increasing values of rotor speed and rotor diameter. The force to break was $34.87 \%$ and $50.76 \%$ higher for the samples B and C respectively with respect to sample A, at constant diameter of $43 \mathrm{~mm}$. In case of rotor diameter, at constant rotor speed of $35,000 \mathrm{rpm}$, the force to break of yarn $17.83 \%$ increased for the sample D and $40.79 \%$ increased for the sample E contrasted to the sample A.

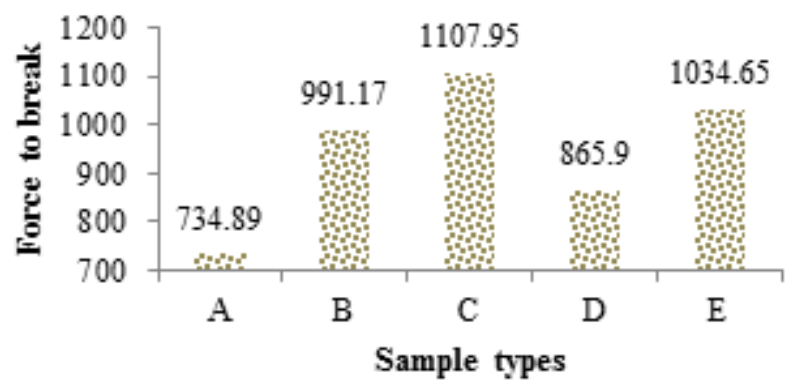

Figure 9. Effect of rotor speed and diameter on yarn force to break

\section{Conclusions}

Significant effect of processing parameters such as rotor speed and rotor diameter on the yarn properties in rotor spinning was studied. The unevenness such as $\mathrm{CVm} \%$, total imperfection index (IPI) and hairiness were improved with augmentation of rotor speed from 35,000 to 45,000 rpm at constant rotor diameter $43 \mathrm{~mm}$. Conversely, reverse scenario observed due to increment of rotor diameter from 43 to $66 \mathrm{~mm}$ at constant rotor speed of $35,000 \mathrm{rpm}$. It appears that the yarn strength i.e. tenacity, CSP and force at break were increased with the increase rotor diameter and running speed. On the basis of imperfections and hairiness the yarn quality tends to deteriorate when the rotor diameter increases from 43 to $54 \mathrm{~mm}$ and rotor speed increases from 40,000 to $45,000 \mathrm{rpm}$ respectively. Further work could be done on producing quality yarn of various counts from other natural, synthetic and blends fibres to justify this analysis.

\section{REFERENCES}

[1] Jackowska-Strumiłło, L., Cyniak, D., Czekalski, J. and Jackowski, T., 2007. Quality of cotton yarns spun using ring-, compact-, and rotor-spinning machines as a function of selected spinning process parameters. Fibres \& Textiles in Eastern Europe, (1 (60)), pp.24-30.

[2] Klein, W., 1995. Manual of Textile Technology. The Textile Institute. Volume 1-6.

[3] Ahmed, S., Syduzzaman, M., Mahmud, M.S., Ashique, S. M. and Rahman, M.M., 2015. Comparative Study on Ring, Rotor and Air-Jet Spun Yarn. European Scientific Journal, 
11(3).

[4] Rameshkumar, C., Anandkumar, P., Senthilnathan, P., Jeevitha, R. and Anbumani, N., 2008. Comparative studies on ring rotor and vortex yarn knitted fabrics. Autex Research Journal, 8 (4), pp.100-105.

[5] Ishtiaque, S. M., 1992. Spinning of synthetic fibres and blends on rotor-spinning machine. Indian Journal of Fibre and Textile Research, 17, pp.224-224.

[6] Nawaz, S. M., Jamil, N. A., Iftikhar, M. and Farooqi, B., 2003. How do open-end processing variables affect imperfections for different yarn count? Pakistan textile journal, pp.22-26.

[7] Manohar, J. S., Rakshit, A. K. and Balasubramanian, N., 1983. Influence of rotor speed, rotor diameter, and carding conditions on yarn quality in open-end spinning. Textile Research Journal, 53(8), pp.497-503.

[8] Md. Khalilur Rahman Khan and Habibur Rahman, 2015. Study of Effect of Rotor Speed, Combing-Roll Speed and Type of Recycled Waste on Rotor Yarn Quality Using Response Surface Methodology" IOSR Journal of Polymer and Textile Engineering (IOSR-JPTE), 2(1), PP 47-55.

[9] Salhotra, K. R. and Balasubramanian, P., 1985. Influence of carding technique on yarn tenacity response to increasing rotor speed. Textile Research Journal, 55(6), pp.381-382.

[10] Sengupta, A. K., Vijayaraghavan, N. and Singh, A., 1983. Studies on carding force between cylinder and flats in a card: Part III-Carding parameters, sliver quality and carding force. Indian J Text Res, 8, p.68.

[11] Özdemir, H. and Oğulata, R. T., 2011. Comparison of the properties of a cotton package made of vortex (MVS) and open-end rotor yarns. FIBRES \& TEXTILES in Eastern
Europe, 19 (1), pp. 37-42.

[12] Ahmed, F., Saleemi, S., Rajput, A. W., Shaikh, I. A. and Sahito, A. R., 2014. Characterization of Rotor Spun Knitting Yarn at High Rotor Speeds. Technical Journal, University of Engineering and Technology (UET), Taxila, Pakistan, 19(IV), pp. 73-78.

[13] Hasani, H. and Tabatabaei, S.A., 2011. Optimizing spinning variables to reduce the hairiness of rotor yarns produced from waste fibres collected from the ginning process. Fibres\& Textiles in Eastern Europe, 19(3), pp.21-25.

[14] Hong, K.H., 2014. Preparation and properties of multifunctional cotton fabric treated by gallnut extract. Textile Research Journal, 84(11), pp. 1138-1146.

[15] Ali, A., Ali, S., Saleem, H. and Hussain, T., 2010. Effect of tannic acid and metallic mordants on the dyeing properties of natural dye extracted from Acacia nilotica bark. Asian Journal of Chemistry, 22(9), pp. 7065-7069.

[16] ASTM D 1776, "Standard practice for conditioning textiles for testing," American Society for Testing and Materials, Annual Book of ASTM Standards, vol. 7(1), ASTM International, West Conshohocken, PA, USA, 2008.

[17] Grosberg, P. and Mansour, S. A., 1975. "Yarn Tension in Rotor-spinning", Journal of the Textile Institute, 66 (6), pp. 228-231.

[18] Retrieved from http://www.slideshare.net/hammamasyed/rotor-machineworking-principle. Accessed on 23-Nov-2016.

[19] Shahid, M.A., Ahmed, F. and Mahabubuzzaman, A.K.M., 2012. Study on the Physical Properties of Jute-Cotton Blended Rotor Yarn. SUST Journal of Science and Technology, 20 (6), pp. 84-88. 